\title{
One year study of efficacy and safety of infliximab in the treatment of patients with ocular and neurological Behçet's disease refractory to standard immunosuppressive drugs
}

\author{
AnnaRita Giardina $\cdot$ Angelo Ferrante $\cdot$ \\ Francesco Ciccia $\cdot$ Maria Vadalà $\cdot$ Ennio Giardina \\ Giovanni Triolo
}

Received: 8 May 2009 / Accepted: 7 October 2009 / Published online: 27 October 2009

(C) Springer-Verlag 2009

\begin{abstract}
The aim of the study was to assess the long-term efficacy and safety of Infliximab therapy in the treatment of patients with Behçet's disease refractory to standard immunosuppressive agents. Twenty-one patients that did not respond to corticosteroids and to at least one immunosuppressant (cyclosporin, methotrexate, azathioprine, cyclophosphamide) for the presence of ocular and/or CNS involvement were enrolled. Eighteen patients completed the study up to 54 weeks. Stable doses of prednisone $(<10 \mathrm{mg} /$ day $)$ were permitted, immunosuppressants were discontinued at least 4 weeks prior baseline visit. The patients received three infusions of $5 \mathrm{mg} / \mathrm{kg}$ Infliximab (at weeks 0,2 and 6) and then infusions of $5 \mathrm{mg} / \mathrm{kg}$ Infliximab every 8 weeks. At each visit data on clinical symptoms, response to therapy and adverse events were collected. The primary outcome of interest was to assess the clinical efficacy (total or partial recovery) of infliximab. Secondary end points were to evaluate quality of life and to monitor the safety of the drug. Eighteen patients achieved a total remission. Two patients achieved a partial remission and relapsed after 3 months from discontinuation of therapy. Infliximab was well tolerated throughout the study. A case of non-Hodgkin lymphoma was observed within 6 months.
\end{abstract}

\footnotetext{
A. Giardina · A. Ferrante · F. Ciccia $\cdot$ E. Giardina $\cdot$ G. Triolo Chair and Division of Rheumatology,

University of Palermo, Palermo, Italy

M. Vadalà

Chair and Division of Ophthalmology,

University of Palermo, Palermo, Italy

G. Triolo $(\bowtie)$

Unità Operativa e Cattedra di Reumatologia,

Piazza delle Cliniche 2, 90127 Palermo, Italy

e-mail: g.triolo@unipa.it
}

Minor side effects were headache, dizziness, tachycardia that regressed spontaneously and did not entail interruption. Anti-nuclear antibodies were not detected during the period of observation.

Keywords Behçet's disease $\cdot$ TNF alfa $\cdot$ Infliximab

\section{Introduction}

Behçet's disease (BD) is a chronic inflammatory disorder affecting various organ systems, characterized by recurrent oral aphthous ulcers, genital ulcers, uveitis, and skin lesions $[1,2]$. All these common manifestations are self-limiting except for the ocular attacks. Repeated attacks of uveitis can cause blindness [1-3]. Involvement of the gastrointestinal tract, central nervous system, and large vessels is less frequent, although it can be life threatening [1, 2, 4-6].

For most patients the treatment of $\mathrm{BD}$ is based on the combination of corticosteroids and immunosuppressive agents [7]. Despite the improvement obtained with this strategy, relapses and failure may occur. Some patients can also be refractory to all treatments.

The aetiology and pathogenesis of $\mathrm{BD}$ are unknown but there are considerable data indicating that immunological abnormalities are important. Several humoral and cellular abnormalities have been described, such as the high serum levels of IL-2, IFN- $\gamma$, TNF- $\alpha$ [8-10]. These cytokines detected in patients with active disease point to a polarized Th1 immune response, as suggested by in vitro and in vivo studies of experimental autoimmune uveoretinitis [11]. We have also documented increased numbers of $\mathrm{T}$ lymphocytes expressing the gammadelta receptor that overproduce TNF in patients with active disease [12] and more recently a role of NF-kB in protecting $\mathrm{T}$ cells against CD95 induced 
apoptosis down-regulated by thalidomide, a TNF inhibiting agent [13].

Case studies have indicated the efficacy of infliximab treatment of patients with BD in refractory ocular [14-16], neurological [17, 18], mucocutaneous [19], and gastroenterological involvement [20, 21].

This study was undertaken to assess the long-term efficacy and safety of anti-tumor necrosis factor $\alpha$ antibody infliximab (Remicade; Centocor Inc, Malvern, PA; Schering Plough SpA, Italy) therapy in the treatment of patients with disease refractory to standard immunosuppressive agents.

\section{Patients and methods}

\section{Patients}

Eligible patients were 18 years of age or older, had active persistent $\mathrm{BD}$ diagnosed according to the international criteria for $\mathrm{BD}$ [22], and a C-reactive protein concentration $>1 \mathrm{mg} / \mathrm{dl}$. Patient inclusion criteria were: failure to respond to corticosteroids and to at least one immunosuppressant (cyclosporin, methotrexate, azathioprine, cyclophosphamide) for the presence of ocular and/or CNS involvement. Major exclusion criteria consisted of prior use of TNF antagonist, a history of active infections or of an episode of major infection within 30 days prior to screening and any uncontrolled medical condition, pregnancy or breast-feeding.

\section{Study protocol}

The study was approved by the local ethics committee. All patients also gave their written informed consent. All patients had a normal chest-X-ray, a negative test for tuberculosis. Stable doses of prednisone ( $<10 \mathrm{mg} /$ day) were permitted, immunosuppressants were discontinued at least 4 weeks prior baseline visit. The patients received three infusions of $5 \mathrm{mg} / \mathrm{kg}$ Infliximab (at weeks 0, 2 and 6) and then infusions of $5 \mathrm{mg} / \mathrm{kg}$ Infliximab, every 8 weeks for a total of 1 year.

Disease and safety assessment

At each visit data on clinical symptoms, response to therapy and adverse events were collected. Responses were defined as: complete $(\mathrm{C})$ when clinical signs of activity, as defined by the BDCAF score [23, 24], that includes the presence of several manifestations of the disease, by the uveitis scoring system and by the visual activity measurement [25], were absent during the 12-month observation; partial (P) when the clinical response was incomplete; absent (A) when clinical manifestations remained stable.
Laboratory evaluation, including erythro-sedimentation rate (ESR), C-reactive protein (CRP), anti-nuclear antibodies and routinary hepatic and renal parameters and complete blood count, was also performed at baseline and before each infusion of Infliximab.

\section{Results}

The primary outcome of interest was to assess the clinical efficacy (total or partial recovery) of infliximab in patients with active disease for whom classical immunosuppressive therapy was insufficient or inappropriate for all clinical manifestation of the disease. Secondary end points were to evaluate quality of life and to monitor the safety of the drug. The total duration of this study was 12 months. Patients who discontinued treatment due to lack of efficacy were considered to be non-responders. Data for patients who discontinued study treatment for other reason (e.g., adverse events) were assessed for treatment response based on their observed values at the time of discontinuation. Twenty-one patients (18 males and 3 females, mean age 36 years, range 18-71) were enrolled into the study. Baseline demographic and clinical characteristics that include BDCAF scores and the result of therapy are shown in Table 1. Organ involvement at presentation included cerebral vasculitis $(n=5)$, retinal vasculitis $(n=13)$ and posterior uveitis $(n=13)$. Other clinical manifestations were oral ulcers $(n=21)$, genital ulcers $(n=12)$, erythema nodosum $(n=7)$. Previous disease-related treatment included prednisone $(n=21)$, cyclosporine $(n=20)$, azathioprine $(n=8)$, cyclophosphamide $(n=2)$, chlorambucil $(n=1)$ methotrexate $(n=3)$, colchicine $(n=8)$ and interferon $(n=1)$. Eighteen patients completed the study up to 54 weeks. Eighteen patients achieved a total remission (Tables 1,2). Twelve of these patients decided to continue infliximab treatment and remained free of symptoms. Six patients discontinued the treatment after 1 year observation and four of them relapsed after 3-6 months. Infliximab was able to control the other disease manifestations. Two patients achieved a partial remission and relapsed after 3 months from discontinuation of therapy. The remission was achieved at a mean time of 4.8 weeks. Three patients withdrew from the study, one for personal reason (at 37th week, responder), one during the 24th week of treatment because of a major adverse event (non-Hodgkin lymphoma, responder) and the last for lack of efficacy (at 12th week). There were no recurrences after steroid tapering. No relationship was observed between the type of response to treatment and the duration of disease or the type of clinical presentation. In all patients, the treatments induced, also, a significant and rapid reduction of laboratory inflammatory parameters (ESR and CRP; not shown). Infliximab was well tolerated throughout the study. 
Table 1 Clinical and demographic characteristics of patients and response to therapy

\begin{tabular}{|c|c|c|c|c|c|c|c|c|c|c|}
\hline \multirow[t]{2}{*}{ Pts } & \multirow[t]{2}{*}{ Sex } & \multirow[t]{2}{*}{ Age } & \multirow[t]{2}{*}{$\begin{array}{l}\text { Age at } \\
\text { diagnosis }\end{array}$} & \multirow[t]{2}{*}{ Previous treatment } & \multirow[t]{2}{*}{$\begin{array}{l}\text { Refractory } \\
\text { manifestations }\end{array}$} & \multirow[t]{2}{*}{$\begin{array}{l}\text { Beginning } \\
\text { of Infliximab }\end{array}$} & \multirow[t]{2}{*}{ Results } & \multirow[t]{2}{*}{$\begin{array}{l}\text { Adverse } \\
\text { events }\end{array}$} & \multicolumn{2}{|c|}{$\begin{array}{l}\text { BDCAF pre- and } \\
\text { after-treatment }\end{array}$} \\
\hline & & & & & & & & & Pre & After \\
\hline 1 & M & 27 & 19 & Co, CsA, P, IFN & PU & July 2003 & $\mathrm{C}$ & - & 7 & 0 \\
\hline 2 & M & 42 & 39 & CsA, P & PU, CV & November 2003 & $\mathrm{C}^{\mathrm{a}}$ & - & 7 & 0 \\
\hline 3 & M & 27 & 24 & CsA, P & PU & November 2002 & $\mathrm{C}$ & - & 6 & 0 \\
\hline 4 & M & 71 & 63 & CsA, P & $\mathrm{CV}$ & May 2003 & $\mathrm{C}$ & Headache & 8 & 0 \\
\hline 5 & M & 41 & 25 & Co, CsA, P & PU & December 2002 & $\mathrm{C}$ & - & 4 & 0 \\
\hline 6 & M & 22 & 21 & CsA, P & PU, RV & September 2003 & $\mathrm{C}$ & - & 6 & 0 \\
\hline 7 & M & 20 & 20 & CsA, P & PU, RV & July 2002 & $\mathrm{C}$ & - & 7 & 0 \\
\hline 8 & M & 23 & 19 & CsA, AZA, P & RV & May 2002 & $\mathrm{C}$ & - & 6 & 0 \\
\hline 9 & M & 41 & 31 & CsA, P & PU, RV & February 2003 & $\mathrm{C}$ & - & 4 & 0 \\
\hline 10 & $\mathrm{~F}$ & 53 & 38 & CsA, AZA, Chl, P & PU, CV & June 2003 & $\mathrm{C}$ & - & 9 & 0 \\
\hline 11 & M & 33 & 32 & CsA, P & RV & April 2004 & $\mathrm{C}$ & - & 6 & 0 \\
\hline 12 & $\mathrm{~F}$ & 38 & 29 & CsA, AZA, P & RV & March 2004 & $\mathrm{C}$ & Dizziness & 7 & 0 \\
\hline 13 & M & 41 & 31 & CsA, AZA, P & $\mathrm{CV}, \mathrm{PU}$ & October 2003 & $\mathrm{C}$ & - & 5 & 0 \\
\hline 14 & M & 32 & 25 & CsA, AZA, P & RV & January 2003 & $\mathrm{C}$ & - & 6 & 0 \\
\hline 15 & M & 28 & 21 & Co, CsA, AZA, P & PU, RV & March 2003 & $A^{b}$ & - & 4 & 3 \\
\hline 16 & M & 39 & 37 & Co, CsA, MTX, P & PU, RV & Sept 2003 & $\mathrm{P}$ & - & 6 & 2 \\
\hline 17 & M & 34 & 31 & Co, CsA, MTX, P & $\mathrm{RV}, \mathrm{PU}$ & February 2003 & $\mathrm{C}$ & - & 10 & 0 \\
\hline 18 & M & 18 & 14 & Co, CsA, CyP, P & $\mathrm{RV}, \mathrm{PU}$ & January 2001 & $\mathrm{C}$ & - & 5 & 0 \\
\hline 19 & $\mathrm{~F}$ & 53 & 45 & $\mathrm{CyP}, \mathrm{P}$ & $\mathrm{CV}$ & January 2003 & $\mathrm{C}^{\mathrm{c}}$ & Lymphoma & 6 & 0 \\
\hline 20 & M & 43 & 33 & Co, CsA, MTX, AZA, P & RV & February 2003 & $\mathrm{C}$ & Tachyardia & 6 & 0 \\
\hline 21 & M & 31 & 16 & Co, CsA, AZA, P & RV & March 2003 & $\mathrm{P}$ & - & 5 & 1 \\
\hline
\end{tabular}

Co colchicine, $C s A$ cyclosporin A, $C y P$ cyclophosphamide, $A Z A$ azathioprine, $C h l$ chlorambucil, $M T X$ methotrexate, $P$ prednisone, $P U$ posterior uveitis, $R V$ retinal vasculitis, $C V$ cerebral vasculitis, $C$ complete remission, $P$ partial remission, $A$ absent remission

${ }^{a}$ Withdrawn at the 37 th week

b Withdrawn at the 12th week

c Withdrawn at the 24th week

Minor side effects were headache, dizziness, tachycardia that regressed spontaneously and did not entail interruption. Anti-nuclear antibodies were not detected during the period of observation.

\section{Discussion}

The primary goals of management of patients with $\mathrm{BD}$ are symptom control, early suppression of inflammation and prevention of end-organ damage, the treatment options being anti-inflammatory agents and immunosuppressants. Drugs are frequently used in combination in order to maximize efficacy while minimizing side effects and the spectrum of clinical manifestations requires close multidisciplinary co-operation for optimal care [26].

Anti-TNF alpha agents have been successfully used in a number of inflammatory conditions other than rheumatoid arthritis, including Crohn's disease, ankylosing spondilytis, psoriasis, psoriatic arthritis and necrotizing vasculitis. The use of infliximab in BD was first described in 2001 [14] and since then a number of case series and single reports have been published. Initial indications for treatment were sightthreatening uveitis and severe inflammatory gastrointestinal disease. Infliximab has subsequently been used for severe orogenital ulceration and for cerebral vasculitis. These anedoctal case studies have generally reported an immediate and dramatic resolution of both organ-specific and systemic symptoms, often in patients refractory to conventional immunosuppression, and, to date, the number of randomized controlled trials in BD is increasing. Differences, however, exist in practical approaches to treatment and the long-term outcome is unknown. Indeed, BD is characterized, generally, by an intermittent course. In these conditions short course or single infusions seem to be sufficient to suppress disease activity for long periods. On the other hand, some patients have a chronic progressive course, recurrent posterior uveitis and retinal and cerebral vasculitis being considered of poor prognosis predictive value, and a sustained therapy is required. 
Table 2 BCVA (best corrected visual acuity expressed as decimal Snellen fraction) and uveitis score in BD patients before and after infliximab treatment

\begin{tabular}{lllll}
\hline PTS & $\begin{array}{l}\text { Pre } \\
\text { BCVA }\end{array}$ & $\begin{array}{l}\text { Post } \\
\text { BCVA }\end{array}$ & $\begin{array}{l}\text { Pre uveitis } \\
\text { score }\end{array}$ & $\begin{array}{l}\text { Post uveitis } \\
\text { score }\end{array}$ \\
\hline 1 & 0.2 & 1 & 4 & 0 \\
2 & 0.2 & 1 & 4 & 0 \\
3 & 0.4 & 1 & 4 & 0 \\
4 & 1 & 1 & 0 & 0 \\
5 & 0.5 & 1 & 3 & 0 \\
6 & 0.4 & 1 & 4 & 0 \\
7 & 0.3 & 0.9 & 5 & 1 \\
8 & 0.6 & 1 & 3 & 0 \\
9 & 0.3 & 1 & 4 & 1 \\
10 & 0.2 & 0.9 & 4 & 0 \\
11 & 0.5 & 1 & 2 & 0 \\
12 & 0.6 & 1 & 2 & 0 \\
13 & 0.2 & 0.7 & 4 & 0 \\
14 & 0.5 & 0.9 & 2 & 0 \\
15 & 0.2 & 0.9 & 4 & 2 \\
16 & 0.05 & 1 & 4 & 1 \\
17 & 0.05 & 0.9 & 6 & 0 \\
18 & 0.05 & 0.8 & 5 & 0 \\
19 & 1 & 1 & 0 & 1 \\
20 & 0.6 & 1 & 2 & 3 \\
21 & 0.6 & 0.8 & 3 & 0 \\
\hline & & & & 0 \\
\hline
\end{tabular}

This study was designed to evaluate the long-term efficacy and safety of anti-tumor necrosis factor $\alpha$ antibody infliximab therapy in the treatment of patients with BD refractory to standard immunosuppressive agents. The primary outcome of interest was to assess the induction of remission, which was achieved in more than $95 \%$ of the patients at a mean time of 4.3 weeks. Importantly, clinical remission was achieved in several patients with persistent disease activity despite dual or triple immunosuppressive therapies. No response was observed in just one patient. This patient was celiac, and it is not known whether this was the result of a failure of infliximab to inhibit TNF mediated responses or a switch to other cytokine pathways as drivers of pathogenesis.

Anti-TNF withdrawn was followed by relapse in the two patients that achieved a partial remission indicating that in these patients a remission induction approach did not produce an optimal response in the medium/long term and after stopping therapy in some responders. Indeed, there have been several other case series providing the observation that patients frequently relapse after anti-TNF discontinuation.

Secondary end point was to monitor the safety of the drug. A patient developed a non-Hodgkin lymphoma. This condition is extremely rare in patients with BD [27] and probably related to anti-TNF therapy. In the other patients infliximab was generally well tolerated during all the period of treatment.

A key target of biological therapy has been inhibition of the cytokine TNF $\alpha$, which has been implicated as a central proinflammatory messenger molecule in immunologically mediated diseases and as a critical cytokine in the physiopathology of BD.

The observation, in this and other studies (reviewed in Ref. [7]), of the dramatic effect of TNF inhibition on reduction of signs and symptoms of disease and on suppression, both in vivo and in vitro, of the number and the function of active lymphocytes implicated in the pathogenesis of $\mathrm{BD}$ [12], induces to consider anti-TNF agents are truly superior to conventional immunosuppressive therapy. Additional randomized placebo-controlled long-term studies of infliximab in BD are warranted, however, using larger patient groups. Furthermore, studies with planned anti-TNF discontinuation would have been much more interesting.

\section{References}

1. Kaklamani VG, Variopoulos G, Kaklamanis PG (1998) Behçet's disease. Semin Arthritis Rheum 27:197-217

2. Nussenblatt RB (1997) Uveitis in Behçet's disease. Int Rev Immunol 14:67-79

3. Nakae K, Masaki F, Hashimoto T, Inaba G, Mochizuki M, Sakane $\mathrm{T}$ (1993) Recent epidemiological features of Behçet's disease in Japan. In: Wechsler B, Godeau P (eds) Behçet's disease. Excerpta Medica, Amsterdam, pp 145-151

4. Zouboulis CC, Kötter I, Djawari D et al (1997) Epidemiological features of Adamantiades-Behçet's disease in Germany and in Europe. Yonsei Med J 38:411-422

5. Dilsen N, Konice M, Aral O, Öcal L, Inanc M, Gill A (1993) Risk factors for vital organ involvement in Behçet's disease. In: Wechsler B, Godeau P (eds) Behçet's disease. Excerpta Medica, Amsterdam, pp 165-169

6. Mamo JG (1970) The rate of visual loss in Behçet's disease. Arch Ophthalmol 84:451-452

7. Pipitone N, Olivieri I, Cantini F, Triolo G, Salvarani C (2006) New approaches in the treatment of Adamantiades-Behçet's diseases. Curr Opin Rheumatol 18:3-9

8. Sayinalp N, Ozcebe OI, Ozdenir O, Haznedaroglu IC, Dundar S, Kirazli S (1996) Cytokines in Behçet's disease. J Rheumatol 23:321-322

9. Frassanito MA, Dammacco R, Cafforio P, Dammacco F (1999) Th1 polarization of the immune response in Behçet's disease: a putative role of interleukin-12. Arthritis Rheum 42:1967-1974

10. Triolo G, Accardo-Palumbo A, Dieli F, Ciccia F, Ferrante A, Giardina E, Licata G (2002) Humoral and cell mediated immune response to cow's milk proteins in Behcet's disease. Ann Rheum Dis 61:459-462

11. Caspi RR (2002) Th1 and Th2 responses in pathogenesis and regulation of experimental autoimmune uveoretinitis. Int Rev Immunol 21:197-208

12. Triolo G, Accardo-Palumbo A, Dieli F, Ciccia F, Ferrante A, Giardina E, Sano CD, Licata G (2003) Vgamma9/Vdelta2 T lymphocytes in Italian patients with Behcet's disease: evidence for 
expansion, and tumour necrosis factor receptor II and interleukin12 receptor beta1 expression in active disease. Arthritis Res Ther 5:R262-R268

13. Todaro M, Zerilli M, Triolo G, Iovino F, Patti M et al (2005) NFkB protects Behçet's disease T cells against CD95 induced apoptosis upregulating anti apoptotic proteins. Arthritis Rheum 52:2179-2191

14. Sfikakis PP, Theodossiadis PG, Katsiari CG, Kaklamanis P, Markomichelakis NN (2001) Effect of infliximab on sight-threatening panuveitis in Behcet's disease. Lancet 28;358(9278):295-296

15. Triolo G, Vadala M, Accardo-Palumbo A, Ferrante A, Ciccia F, Giardina E, Citarrella P, Lodato G, Licata G (2002) Anti-tumour necrosis factor monoclonal antibody treatment for ocular Behcet's disease. Ann Rheum Dis 61:560-561

16. Al-Rayes H, Al-Swallen R, Al-Balawi M et al (2008) Safety and efficacy of infliximab therapy in active Behçet's uveitis: an openlabel study. Rheumatol Int 29:53-57

17. Licata G, Pinto A, Tuttolomondo A, Banco A, Ciccia F, Ferrante A, Triolo G (2003) Anti-tumor necrosis factor alpha monoclonal antibody therapy for recalcitrant cerebral vasculitis in a patient with Behçet's syndrome. Ann Rheum Dis 62:280-281

18. Pipitone N, Olivieri I, Padula A et al (2009) Infliximab for the treatment of neuro-Beheçet's disease: a case series and review of the literature. Arthritis Rheum 59:285-290

19. Goossens PH, Verburg RJ, Bredveld FC (2001) Remission of Behçet's syndrome with tumour necrosis factor $\alpha$ blocking therapy. Ann Rheum Dis 60:637
20. Hassard PV, Binder SW, Nelson V, Vasiliauskas EA (2001) Antitumor necrosis factor monoclonal antibody therapy for gastrointestinal Behcet's disease: a case report. Gastroenterology 120:995-999

21. Travis SP, Czajkowski M, McGovern DP, Watson RG, Bell AL (2001) Treatment of intestinal Behcet's syndrome with chimeric tumour necrosis factor alpha antibody. Gut 49:725-728

22. International Study Group for Behçet's Disease (1990) Criteria for diagnosis of Behçet's disease. Lancet 335:995-999

23. Bahcta BB, Brennan P, James TE, Chamberlain A, Noble BA, Silman AJ (1999) Behçet's disease: evaluation of a new instrument to measure clinical activity. Rheumatology 38:728-735

24. Lawton G, Bahcta BB, Chamberlain AA, Tennant A (2004) Behçet's disease activity index. Rheumatology 43:73-78

25. Jabs DA, Nussenblatt RB, Rosenbaum JT (2005) Standardization of uveitis nomenclature (SUN) working group, Standardization of uveitis nomenclature for reporting clinical data Results of the first international workshop. Am J Ophtalmol 140:509-516

26. Hatemi G, Silman A, Bang D, Bodaghi B et al (2008) EULAR recommendations for the management of Behçet's disease: report of a task force of the European Standing Committee for International Clinical Studies Including Therapeutics (ESCISIT). Ann Rheum Dis

27. Katsura Y, Suzukawa K, Kojima H, Yoshida C, Shimizu S, Mukai H, Hasegawa Y, Imagawa S, Mori N, Nagasawa T (2003) Cytotoxic T-cell lymphoma arising in Behcet disease. Int J Hematol 77:282-285 